\title{
A New Method for Estimating Off-Shore Wind Potentials
}

\section{Sørensen, Bent}

Published in:

International Journal of Green Energy

DOI:

$10.1080 / 15435070802106894$

Publication date:

2008

Document Version

Early version, also known as pre-print

Citation for published version (APA):

Sørensen, B. (2008). A New Method for Estimating Off-Shore Wind Potentials. International Journal of Green Energy, 5(3), 139-147. https://doi.org/10.1080/15435070802106894

\section{General rights}

Copyright and moral rights for the publications made accessible in the public portal are retained by the authors and/or other copyright owners and it is a condition of accessing publications that users recognise and abide by the legal requirements associated with these rights.

- Users may download and print one copy of any publication from the public portal for the purpose of private study or research.

- You may not further distribute the material or use it for any profit-making activity or commercial gain.

- You may freely distribute the URL identifying the publication in the public portal.

\section{Take down policy}

If you believe that this document breaches copyright please contact rucforsk@kb.dk providing details, and we will remove access to the work immediately and investigate your claim. 


\section{A NEW METHOD FOR ESTIMATING OFF-SHORE WIND POTENTIALS}

\section{Bent Sørensen}

Roskilde University, Energy. Environment and Climate Research Group, Department of Environmental, Social and Spatial Change, Universitetsvej 1, Bld. 11.1, PO Box 260, DK-4000 Roskilde, Denmark

Exploitation of wind energy is currently near economic viability at many sites including coast-near locations on- or off-shore. Because meteorological measuring stations are largely placed on land, the estimation of potential production from offshore sites is more difficult and has been unreliable in predicting the precise advantage of the more consistent and higher wind speeds known to prevail over sea (Sørensen, 2004). A new method for off-shore wind power prediction is presented here, based on sweeping microwave radar ("scatterometer") measurements by satellite, that provide radar wind data from reflections by the sea surface or air-borne water particles over the sea surface. The original purpose of these satellite missions was to explore sea-atmosphere interactions that are important for climate modelling (Chelton et al., 2004).

\section{DEFINING THE PROBLEMS ADDRESSED}

Current projects of off-shore wind power extraction typically involve propeller-type turbines with hub heights of the order of $100 \mathrm{~m}$ above sea level and placed on foundations at a water depth of up to $50 \mathrm{~m}$. During the last decade, microwave scatterometer measurements of the effects of wind stresses on ocean surfaces have 
reached continuous, global coverage and improved accuracy in deriving near-surface wind speeds and directions from the radar reflection signals received at the satellite. The Seawinds instrument on the QuickSCAT satellite has provided such data since mid1999 (NCAR, 2006). Its sweeping pencil beams of microwave radiation emitted from the satellite have a frequency of $13.4 \times 10^{9} \mathrm{~s}^{-1}$ corresponding to a wavelength of 0.022 m. This frequency lies in a band known for the smallness of atmospheric attenuation (allowing a simplified subtraction of such effects (Freilich, 1997)) en route from and back to the satellite.

The footprint of each pencil beam from the spinning parabolic antenna of the Seawinds system has an about $30 \mathrm{~km} \times 35 \mathrm{~km}$ elliptical area at the ocean surface. From a volume with this area and a certain height, the satellite receives a reflected radar signal. In fact, there are two transmitters and receivers operating at different azimuth angles, offering two looks at the same ocean area at short time intervals and thereby allowing an over-determination of wind velocities, that is used to eliminate ambiguities in the directional solutions inherent in the algorithms used and improve accuracy.

Conventionally, the reflections from the ocean surfaces are considered to arise from wind-generated capillary ripples on top of wave patterns, as well as from the wave and generally ocean surfaces. Capillary waves may be defined (Sørensen, 2004) as those with wavelengths under some $0.02 \mathrm{~m}$, i.e. with wavelength lower than or similar to that of the microwave beam used. However, additional sources of reflection may be whitecaps and water spray particles often fairly abundant at heights up to around $20 \mathrm{~m}$ above the sea surface, but radiation at the beam frequency used would be rather insensitive (Ulaby et al., 1981) to water particles much smaller than $0.01 \mathrm{~m}$. Of the 
sources mentioned, the capillary waves are most directly linked to instantaneous wind stress, whereas gravity waves represent accumulated wind influence over periods that may involve many hours or even days, as evidenced by waves persisting long after the wind has quieted down. Like all moving sources, ocean currents induce a Doppler shift, unrelated to wind, in the microwave radar reflections. Rain en route to or from the satellite will, depending on its intensity, blur the radar signal, and it is usual to eliminate or use models to correct wind measurements affected by strong rain (Marzano et al., 2000; Milliff et al., 2004).

Because the backscattered signal averages over all of the mentioned processes within a volume equal to the kilometre-sized footprint times a height of some metres, one cannot identify a single type of reflection process as the source, but one does note a high sensitivity to the combined expressions of near-surface winds, implying that the wind vector extracted by use of the radar equation may have interesting applications.

Going from the wind speeds near the ocean surface to the productivity of megawatt wind turbines involves two additional calculations. One is to determine the height-profile of the wind speeds and the other to fold the wind-speed data with the conversion characteristics of a typical wind turbine. The height profile is that of a flow over a surface of a certain level of roughness. It may be described by the MoninObukhov relations (Monin and Obukhov, 1954) derived from classical fluid dynamics and containing as parameters the friction velocity of the air (a parameter of dimension length, the square of which equals the surface wind stress over the air density) and a second parameter describing the stability of the air. The air stability parameter more precisely describes the transport of heat across a unit area in the atmosphere. If this transport is zero, the atmosphere is said to be stable and in that case the height dependence of wind speeds is a simple logarithmic scaling law (Sørensen, 2004). 
For use in estimating power production from wind turbines it is customary to scale wind speeds to the turbine hub height by use the scaling law for a stable atmosphere, as the error is considered low due to insensitivity at both low and high wind speeds. The output from a typical propeller-type horizontal-axis wind turbine is zero for wind speeds below a threshold (say $5 \mathrm{~ms}^{-1}$ ), then rises to a maximum (at about $12 \mathrm{~ms}^{-1}$ wind speed), and stays there at higher wind speeds, until the turbine is shut down for safety reasons at high wind speeds (say above $25 \mathrm{~ms}^{-1}$ ).

\section{DETAILS OF THE METHODS USED}

Monthly year-2000 6h-satellite scatterometer data downloaded from NCAR (2006) were uniformly scaled (by 1.3 for the illustrations presented here) and converted to wind turbine outputs by a power curve linearly rising from 0 to $450 \mathrm{Wm}^{-2}$ between $5 \mathrm{~ms}^{-1}$ and $12 \mathrm{~ms}^{-1}$, staying at $450 \mathrm{Wm}^{-1}$ until $25 \mathrm{~ms}^{-1}$ and then dropping to zero again. The roughness parameter used in the scaling law for the Dutch off-shore site (Figure 1) is $0.0001 \mathrm{~m}$. Monthly and annual average values were placed on a geographical grid of $0.5^{\circ}$-resolution on both axes and displayed using the Mollweide projection of the Earth in order that the areas with a given wind potential are faithfully represented (at the expense of a variable vertical-line distortion), and thus can be simply added or integrated. For the plots including wind direction, a Mercator projection was used in order to achieve some similarity to conventional wind rose plots. Wind directions are not used in the potential power production calculations, assuming wind turbines with perfect yaw. This assumption is fulfilled in praxis, as any yawing adjustment to a new wind direction can be achieved in at most a few minutes by the present-generation, large wind turbines. 


\section{RESULTS OBTAINED}

Figure 1 shows a January 2000 time series of wind turbine outputs calculated from the scatterometer satellite data by the methods described above, and outputs calculated from measured wind speeds for the same sequence of 6-hour intervals (Royal Dutch Meteorological Institute, 2006). The location is about $100 \mathrm{~km}$ off-shore from the Dutch coast, at one of the few off-shore locations where data are available at a height suitable for wind power exploitation (74 $\mathrm{m}$ above the sea). The wind speed scaling factor that makes the satellite data reproduce the total power production over the period derived from the measured wind speeds is 1.3 . Whereas no other publicly available data were found to allow such a direct comparison, some 1995-data from measurements performed as a prelude to the installation of Danish off-shore wind farms have been compared to the predictions from the year-2000 satellite data (Sørensen, 2007). There is of course no detailed similarity between passages of weather fronts during a given calendar period in different years, but the overall picture of variability is found similar, and the wind speed scaling factor of 1.3 again reproduces the accumulated power production with an accuracy that suggests that such predictions may be used generally for of identification of suitable sites for off-shore wind installations.

The spatial resolution of the primary extracted scatterometer winds (Freilich, 1997) is roughly $25 \mathrm{~km}$. Due to the intermittent passage of the satellite over a given location, these data have been blended with calculated wind speeds from general circulation models adapted to measured wind data on land (Kalney et al., 1996; Milliff et al., 1999), in such a way that high-frequency variability from the scatterometer data is retained, while circulation model data are used for interpolation between satellite 
sweeps over a given location (the $1800 \mathrm{~km}$ wide QuickSCAT sweeps take 101 minutes and a given location is measured at about $12 \mathrm{~h}$ intervals). The resulting 6-hourly data thus gets high-quality input at each second time step, but only over water. For land-sites the radar reflections may come from a multitude of sources and the satellite data cannot be used to estimate wind speeds. The blended data are presented at a grid of $0.5^{\circ} \times 0.5^{\circ}$, combining the scatterometer swath resolution approaching $25 \mathrm{~km}$ with the results from the general circulation model that if used alone would have an output resolution of the order of $250 \mathrm{~km}$ (for an input integration-step grid with $0.5^{\circ}=56 \mathrm{~km}$ latitude grid-sides and for longitudinal grid-sides multiplied by the cosine to the latitude). For locations on land, the circulation model data are clearly unsuited for placement of wind turbines, but may give a fair indication of the wind potential of an extended region (Sørensen, 2004). The ocean and near-shore (from the sea side) blended data, on the other hand, offers a clear improvement over any existing method of estimating wind power potential at these locations. Because of the finite grid size used in presenting the blended data, some blended data points along a given shore-line (on both land and water sides) could represent circulation model calculations of low resolution rather than the high-resolution scatterometer readings. The off-shore location used in Figure 1 is sufficiently far from land to exclude any such problems.

Having established a scaling factor close to 1.3 in going from the primary scatterometer data to a height of $74 \mathrm{~m}$, one can use the Monin-Obukhov theory to determine the average effective height $z_{1}$ associated with the scatterometer data, a quantity that is otherwise not easy to assess, because the wind extraction method used in analysing scatterometer data involves a search for the best solution under assumptions of simple stochastic distributions for the backscattered rays and without considering a 
particular height (Freilich, 1997). To estimate $z_{1}$, one may use the logarithmic scaling law describing stable atmospheric situations, $v_{2} / v_{1}=\log \left(\left(z_{2}+z_{0}\right) / z_{0}\right) / \log \left(\left(z_{1}+z_{0}\right) / z_{0}\right.$, where $v_{1}$ and $v_{2}$ are wind speeds at heights $z_{1}$ and $z_{2}$, log is the natural logarithm and $z_{0}$ the roughness length for the ocean surface (Sørensen, 2004), related to the friction velocity and as stated being about $0.0001 \mathrm{~m}$ for the Dutch site (Royal Dutch Meteorological Institute, 2006). Because the Dutch measurements include this estimate of the roughness length $z_{0}$ at the particular off-shore location, the scaling law for a neutral atmosphere stated above contains one remaining unknown quantity, the reference height, which is then found to be $3 \mathrm{~m}$ (representing the height over the average sea surface that the satellite winds on average pertain to). This estimate is considered more accurate than one based upon speculations on the particular scattering objects involved, because it is based on long-term averages of a power calculation sensitive only to the most common mid-size wind speeds.

\section{USES OF METHOD PROPOSED}

The 6-hourly time series constructed from the satellite data may be used to assess the variability of wind power with time and location, and hence any need for interregional power trading or for establishing energy stores (Sørensen, 2007). Short-term fluctuations (under one hour) are smoothed by dispersing wind turbine locations over a few hundred kilometres, but smoothing over longer periods required power transmission between regions of different weather (and hence wind) regimes, implying distances of some $500 \mathrm{~km}$ or more. In addition to use of the time series, averages over time can be used to assess wind power production potentials over periods from weeks to years. Decisions to build wind turbine parks are often taken on the basis of expected average annual production, and a global map of such production potentials is shown in Figure 2. 
As stated above, the accuracy over land is low and values shown should be taken as indicative only for large regions. For off-shore locations, the spatial resolution is quite acceptable due to the absence of abrupt roughness variations. The variations in power production over the year may also be a factor considered in planning off-shore wind parks, and figures like Figure 2 but for each month of the year is provided as an animation found in the supplementary material. The electronic version of Figure 2 also allows enlarging the figure to show more details of a particular region of the world. Averages similar to Figure 2 but for the wind speeds rather than turbine output power have been published (Jet Propulsion Laboratory, 2007; Risien and Chelton, 2006)), but they are not suited for wind turbine power estimates, due to the non-linear power curve that excludes deriving accurate average power levels from average wind speeds (cf. discussion in Sørensen, 2004).

Figure 2 first of all emphasises the huge advantage of producing wind power over water, and not only at mid-ocean locations but right into the shore-regions of several continents. However, it also indicates that a number of coastal sites are less suitable, notably sites on the western side of continents near the Equator and on both sides of Equatorial sites south and south-east of the Asian continent. Closer inspection of shore lines further away from the Equator shows notable differences in the generally large wind potentials, with a number of very high-potential coastlines in all continents not yet considered for energy exploitation. Of course, additional factors may influence suitability for constructing power facilities, such as whether the water depth increases more or less rapidly away from the shore. Further, a number of inland-water systems stand out as highly suitable for wind power, including the Great Lakes in North 
America, the Baltic Sea and parts of the Mediterranean Sea in Europe, the Caspian and Aral Seas near the Europe-Asia border and Lake Victoria in Africa.

\section{DISCUSSION OF OTHER APPLICATIONS}

To address wind turbine operational issues such as the need for power exchange between regions or storage (Sørensen, 2007), the blended data offer 6-hourly calculations of both the expected power output and the direction from which the turbine must accept winds. Figures 3 and 4 show two examples from such a sequence of $6 \mathrm{~h}$ data, for a region in the North Atlantic Ocean. Figure 3 shows the situation on January 20, year 2000, where a cyclone with centre West of Ireland give rise to high potential wind power production on the East costs of the USA and Greenland, and on the British Isles and the West coasts of continental Europe, Finland in the Baltic and Greece in the Mediterranean Sea. Other parts of Europe might have to import power from these regions. The situation at the end of the week, on January 26, is shown in Figure 4. Now there is a storm blowing from SW at the Florida coast and turning to West as it reaches the British Isles and Scandinavia. These countries and Germany are seen to be capable of producing large amounts of power, while France, Central Europe and the Mediterranean countries except for a few South-facing costs have a need to import power or use alternative solutions (Sørensen, 2007). These examples indicate some modes of application made available by the quality data from the scatterometer satellite measurements.

\section{REFERENCES}

Chelton, D., Schlax, M., Freilich, M., Milliff, R. (2004). Satellite measurements reveal persistent small-scale features in ocean winds. Science, 303, 978-983. 
Freilich, M. (1997). SeaWinds Algorithm Theoretical Basis Document (undated, probably 1997). Available as atbd-sws-01.pdf from the Jet Propulsion Laboratory website http://podaac.jpl.nasa.gov/quicksat/qscat-doc/html Jet Propulsion Laboratory. (2007). SeaWinds on QuickSCAT Products. Download website http://podaac.jpl.nasa.gov/cgi-bin/dcatalog/ (last assessed 2007).

Kalnay, E., Kanamitsu, M., Kistler, R., Collins, W., Deaven, D., Gandin, L., Iredell, M., Saha, S., White, G., Wollen, J., Zhu, Y., Chelliah, M., Ebisuzaki, W., Higgins, W., Janowiak, J., Mo, K., Ropelewski, C., Leetmaa, A., Reynolds, R., Jenne, R. (1996). The NCEP/NCAR 40-year reanalysis project. Bull. Am. Met. Soc. 77, 437-471.

Marzano, F., Roberti, L., Mugnai, A. (2000). Impact of rainfall incoherent backscattering upon radar echoes above 10 GHz. Phys. Chem. Earth (B) 25, 943-948. Milliff, R., Large, W., Morzel, J., Danabasoglu, G., Chin, T. (1999). Ocean general circulation model sensitivity to forcing from scatterometer winds. J. Geophys. Res. 104, 11337-11358.

Milliff, R., Morzel, J., Chelton, D., Freilich, M. (2004). Wind Stress Curl and Wind Stress Divergence Biases from Rain Effects on QSCAT Surface Wind Retrievals, $J$. Atmos. Ocea. Tech. 21, 1216-1231.

Monin, A., Obukhov, A. (1954). Trudy Geofizicheskova Instituta, Akademiya Nauk SSSR, No. 24 (151).

National Center for Atmospheric Research (2006). Data Support Section. QSCAT/NCEP Blended Ocean Winds ds744.4.The not blended QSCAT dataset is ds744.2. Data download site http://dss.ucar.edu/datasets/ds744.4/ (accessed for download June 2006). 
Risien, C., Chelton, D. (2006). A satellite-derived climatology of global ocean winds. Remote Sensing of Environment 105, 221-236.

Royal Dutch Meteorological Institute (2006). HYDRA Project, data available at website: http://www.knmi.nl/samenw/hydra (assessed July 2006).

Sørensen, B. (2004). Renewable Energy, $3^{\text {rd }}$ ed., Elsevier Academic Press, Burlington (946 pp).

Sørensen, B. (2007). A sustainable energy future: Construction of demand and renewable energy supply scenarios. Int. J. Energy Res. (accepted for publication).

Ulaby, F., Moore, R., Fung, A. (1986). Microwave remote sensing. Addison-Wesley, Reading, vol. 1 (1981), vol. 2 (1982), vol. 3. 


\section{FIGURES AND CAPTIONS}
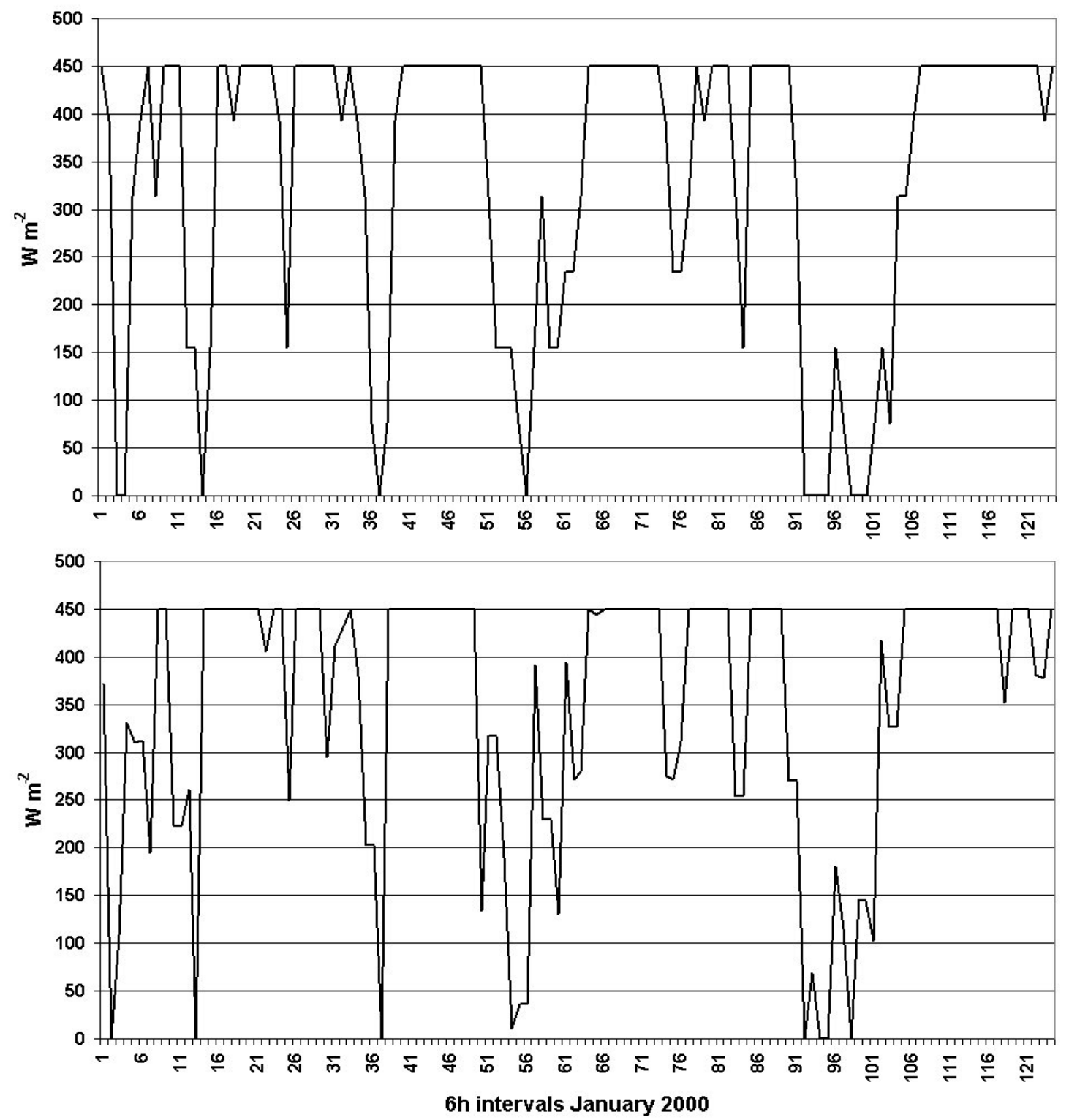

Figure 1. Measured time series of wind power output at the off-shore Dutch location Station 252 K3 during January 2000 (upper panel9) and corresponding $6 \mathrm{~h}$ wind turbine power calculated from scatterometer blended data for (lower panel). The average power for the month is $336 \mathrm{~W} \mathrm{~m}^{-2}$ (measured) and $346 \mathrm{~W}$ $\mathrm{m}^{-2}$ (calculated). 


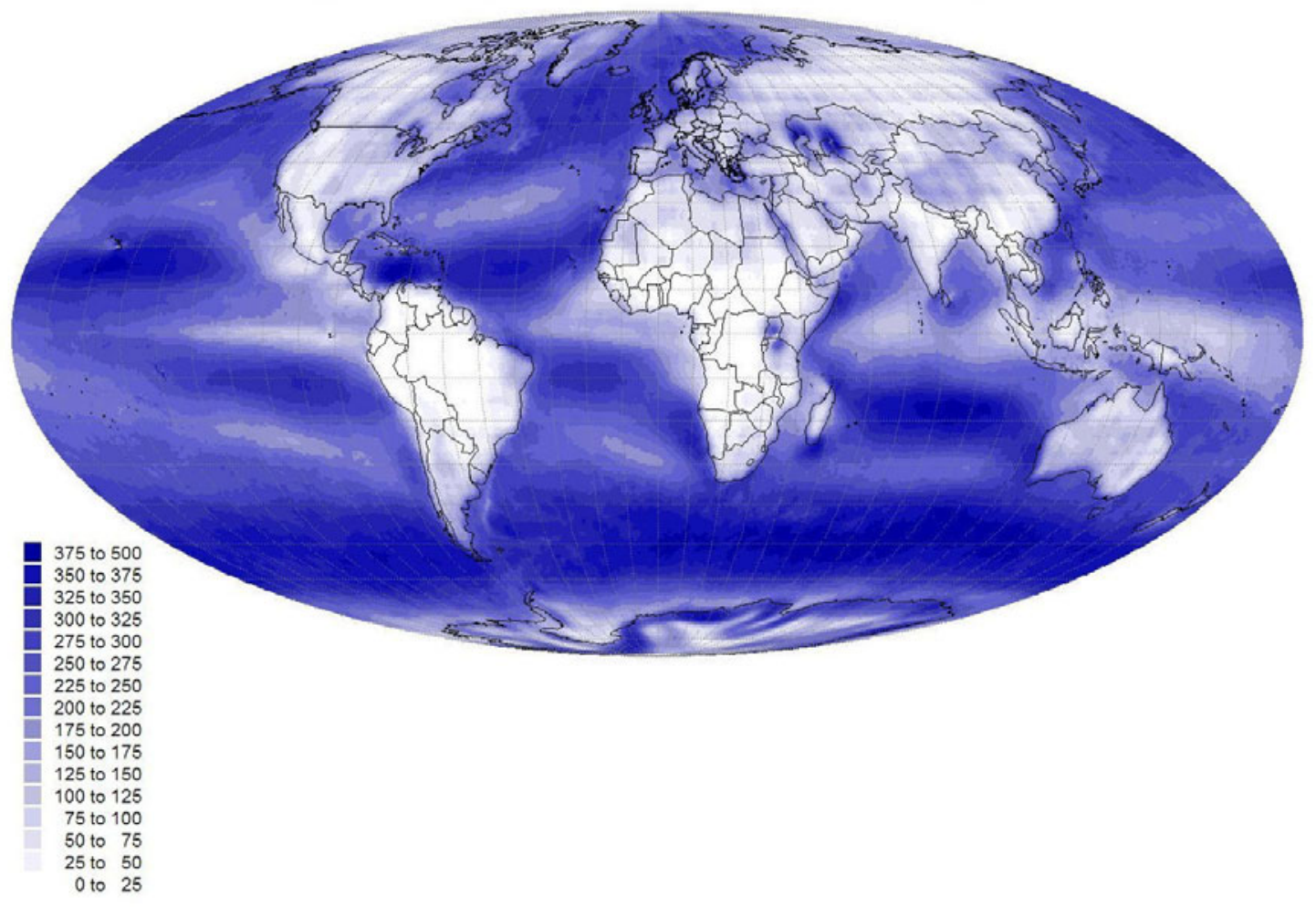

Figure 2. Global map of wind resources expressed as average potential power production during year 2000 , based on blended scatterometer data model with a scaling factor of 1.3 and a power conversion curve typical of current wind turbines. The unit is average watts per $\mathrm{m}^{2}$ of swept turbine area. 

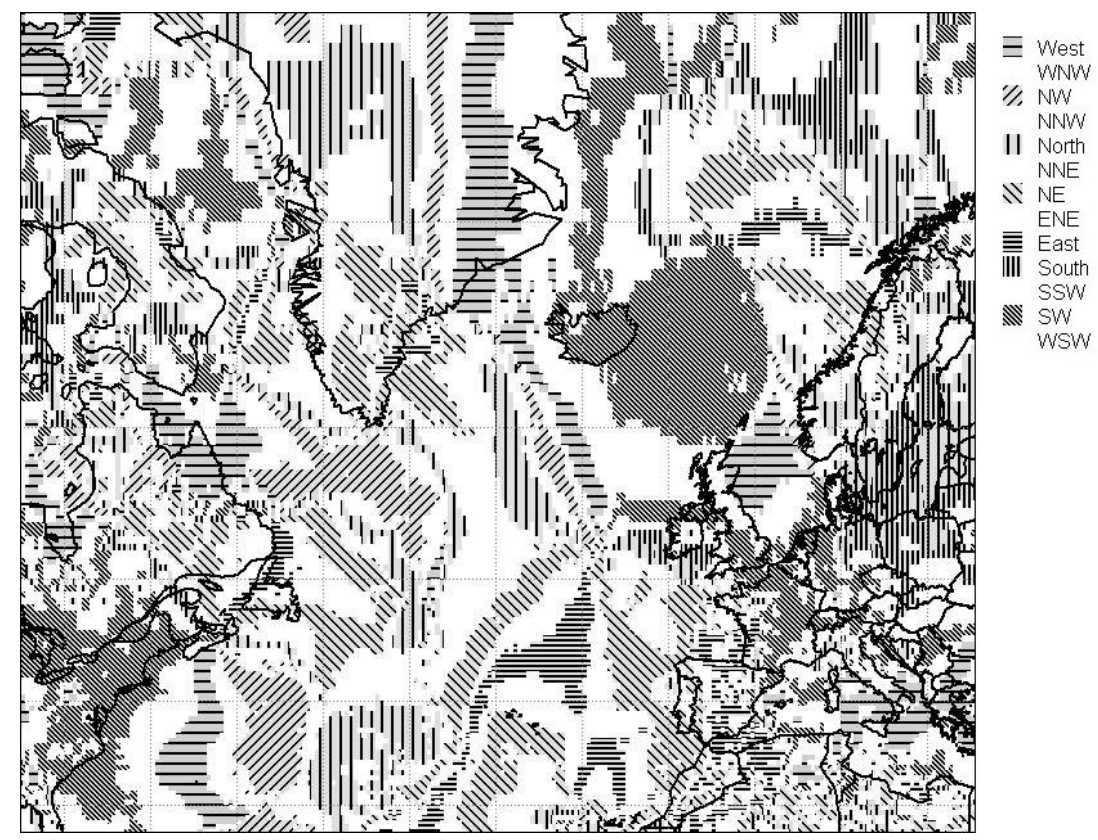

(a)
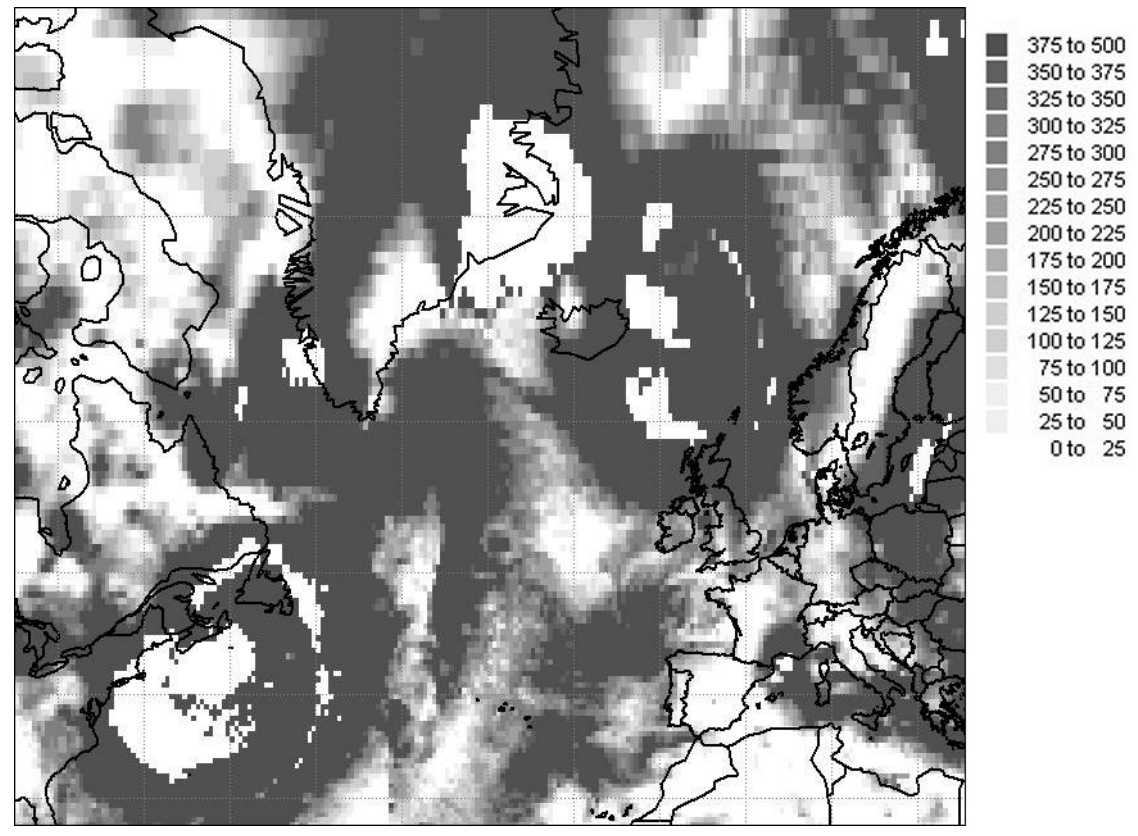

(b)

Figure 3. Plot of wind directions (a) and calculated potential power production (b) (W per $\mathrm{m}^{2}$ of turbine-swept area) based on satellite data for the North Atlantic Ocean and adjacent land areas, on January 20, 2000, at 18h GMT. The abrupt changes from maximum power output to zero output (white areas) are due to the assumption that for safety reasons, wind turbines are shut down if the wind speed exceeds $25 \mathrm{~m} \mathrm{~s}^{-1}$. 


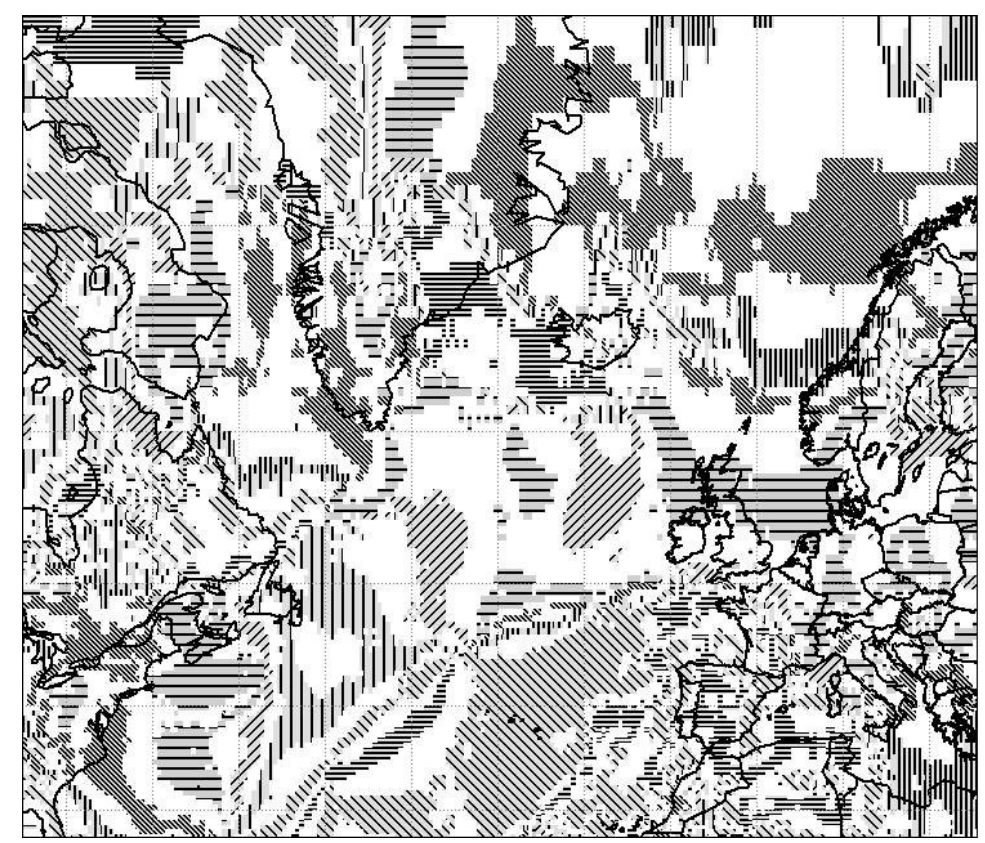

三 West
WNW
NW

NNW

NN NE

ENE
$\overline{\text { EIIII East }}$ South

SW

WSW

(a)

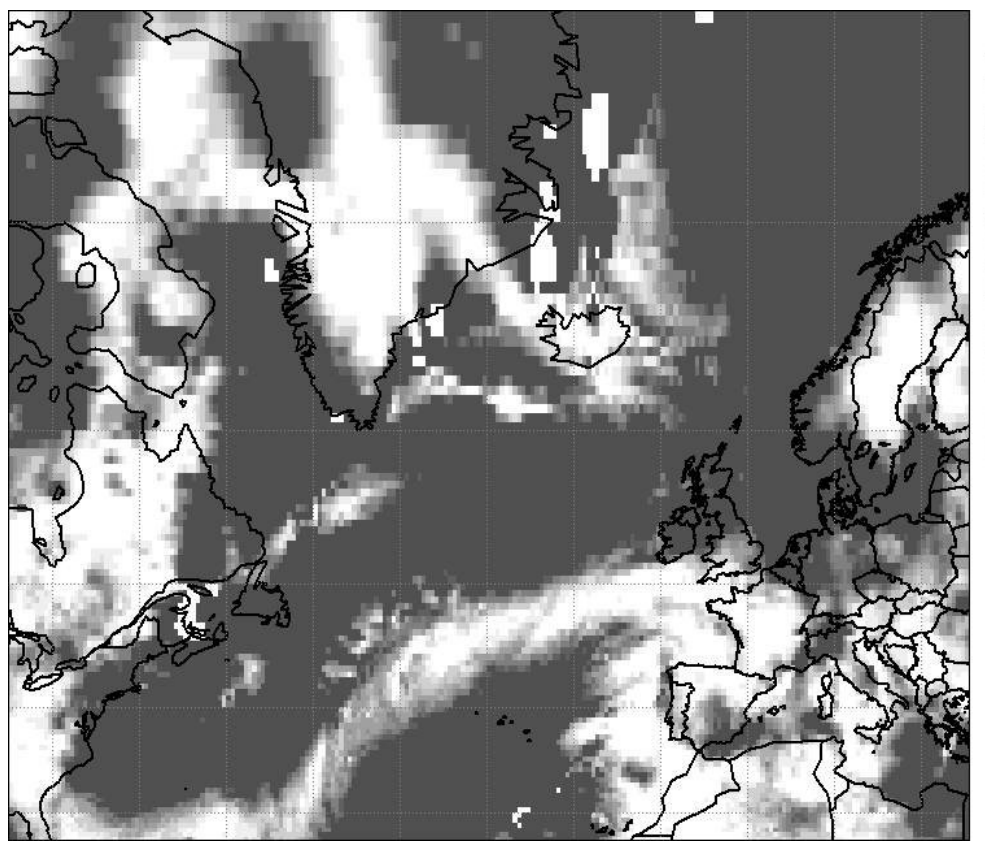

375 to 500

350 to 375

325 to 350

300 to 325

275 to 300

250 to 275

225 to 250

200 to 225

175 to 200

150 to 175

125 to 150
100 to 125

75 to 100

50 to 75

25 to 50

0 to 25

(b)

Figure 4. Same as Figure 3 but for January 26, also at 18 h GMT. 